\title{
Common and critical inflammatory dermatoses every pathologist should know
}

\author{
Steven D. Billings ${ }^{1}$
}

Received: 16 July 2019 / Revised: 8 October 2019 / Accepted: 8 October 2019 / Published online: 1 November 2019

(c) The Author(s), under exclusive licence to United States \& Canadian Academy of Pathology 2019

\begin{abstract}
Inflammatory dermatopathology remains a challenging area for surgical pathologists. Yet every surgical pathologist encounters inflammatory dermatoses as part of routine practice. This review will focus on selected diagnoses that are either commonly encountered in the routine practice of surgical pathology or are critically important. The following entities will be covered: spongiotic dermatoses, lichen simplex chronicus, and early lichen sclerosus in the setting of vulvar biopsies, as well as graft versus host disease, Stevens-Johnson syndrome/toxic epidermal necrolysis, granuloma anulare, pyoderma gangrenosum, and calciphylaxis. Practical points and key histologic features will be emphasized.
\end{abstract}

\section{Introduction}

Inflammatory dermatoses are consistently one of the most challenging areas in dermatopathology for general surgical pathologists. There is significant overlap in histologic features that often causes diagnostic difficulty. Furthermore, the language of dermatopathology often borders on the impenetrable. Contributing to the trepidation that pathologists feel toward dermatopathology is their own limited training. During residency training, a pathology resident may only have a limited exposure to dermatopathology. According to one study, pathology residencies averaged $216.5 \mathrm{~h}$ ( $\sim 9$ days) of dermatopathology training over the course of four years, with an average of only $54.1 \mathrm{~h}$ per year of training [1]. Not surprisingly, with that level of exposure, many pathologists feel uncomfortable with dermatopathology, especially inflammatory dermatoses. With that relatively paltry amount of training, one would think that dermatopathology would be an infrequent aspect of routine practice. In practice, that is not the case. Skin specimens remain one of the most commonly encountered specimen classes for pathologists.

Steven D. Billings

billins@ccf.org

1 Department of Pathology Cleveland Clinic 9500 Euclid Ave L25, Cleveland, OH 44195, USA
While most pathologists, feel relatively comfortable with cutaneous neoplasms, inflammatory dermatoses are a frequent source of diagnostic anxiety. In my experience pathologists often rely on overly vague descriptive diagnoses such as "nonspecific chronic dermatitis" or "parakeratosis with significant acute and chronic inflammation and reactive changes" when faced with inflammatory conditions. While these descriptive diagnoses may be technically speaking accurate, they are not typically helpful to the clinician in managing the patient. More helpful is a descriptive diagnosis that can be at least slotted into one of the common inflammatory reaction patterns encountered in dermatopathology. Indeed, once the appropriate pattern is recognized, it is often possible to make a specific rather than descriptive diagnosis. This approach was made popular through the textbooks on the subject from the late Dr. A. Bernard Ackerman [2,3] and is present in almost all dermatopathology textbooks that deal with inflammatory diseases. This review will focus on eight inflammatory dermatoses with which every pathologist should be familiar: spongiotic dermatitis, lichen simplex chronicus, early lichen sclerosus, graft versus hosts disease, toxic epidermal necrolysis, granuloma annulare, pyoderma gangrenosum, and calciphylaxis.

\section{Spongiotic dermatitis}

In my personal experience, spongiotic dermatitis is often encountered by non-dermatopathologists in the setting of vulvar biopsies. In the setting of vulvar disease, contact 
dermatitis, both irritant and allergic, and atopic dermatitis are the most common sources of spongiotic dermatitis [4-7]. Irritant contact dermatitis is the result of a direct irritation to the skin. Common agents can include urine, feminine hygiene products, soaps and detergents, and alcohol-based creams and gels. Allergic contact dermatitis is secondary to a type IV hypersensitivity reaction. Common triggers include topical anesthetics, topical antimicrobials, chemical substances in douches, fragrances, and chemicals associated with sanitary napkins. Atopic dermatitis is a complex an incompletely understood process that results from interactions between genetic and environmental factors that contribute to defects in the normal skin barrier function [4].

From a microscopic perspective contact dermatitis and atopic dermatitis show significant overlap [5]. This spectrum of microscopic findings exist along a continuum that is artificially separated into three categories: acute, subacute, or chronic spongiotic. Acute spongiotic dermatitis typically has a normal basket-weave stratum corneum overlaying an epidermis that has an accumulation of edema fluid within the epidermis resulting in the keratinocytes being stretched apart so that the intercellular desmosomal attachments are visualized. In severe cases, spongiotic microvesicles, formed by rupture of some of the desmosomal attachments may be seen (Fig. 1a). Typically within the dermis there is a superficial perivascular inflammatory infiltrate that is predominantly composed of lymphocytes with variable numbers of histiocytes and eosinophils. Given this anatomic location, plasma cells are not uncommonly seen as well.

As the process persists, the epidermis reacts to the inflammatory agent by undergoing increased proliferation, resulting in the histologic changes associated with subacute and chronic spongiotic dermatitis. In subacute spongiotic dermatitis, the stratum corneum contains parakeratosis, and the epidermis is acanthotic (hyperplastic) and has a diminished granular layer (Fig. 1b). There is still spongiosis of the epidermis, but microvesicles are uncommon. Within the dermis there is a similar inflammatory infiltrate but typically without dermal edema. In chronic spongiotic dermatitis, there is usually compact hyperkeratosis, sometimes with focal parakeratosis, a thickened granular layer, and acanthosis. Intraepidermal spongiosis is minimal to mild (Fig. 1c). Within the dermis there is a similar inflammatory infiltrate, but the superficial dermis may be somewhat fibrotic.

From a histologic standpoint, contact dermatitis and atopic dermatitis may be identical. Atopic dermatitis is less likely to present as an acute spongiotic dermatitis, but biopsies of spongiotic dermatitis in the acute phase are rare. Most are biopsied in the subacute to chronic phase. A potential clue to the diagnosis of an irritant contact dermatitis is the presence of dyskeratotic cells in the upper half of the epidermis. For allergic contact dermatitis, the
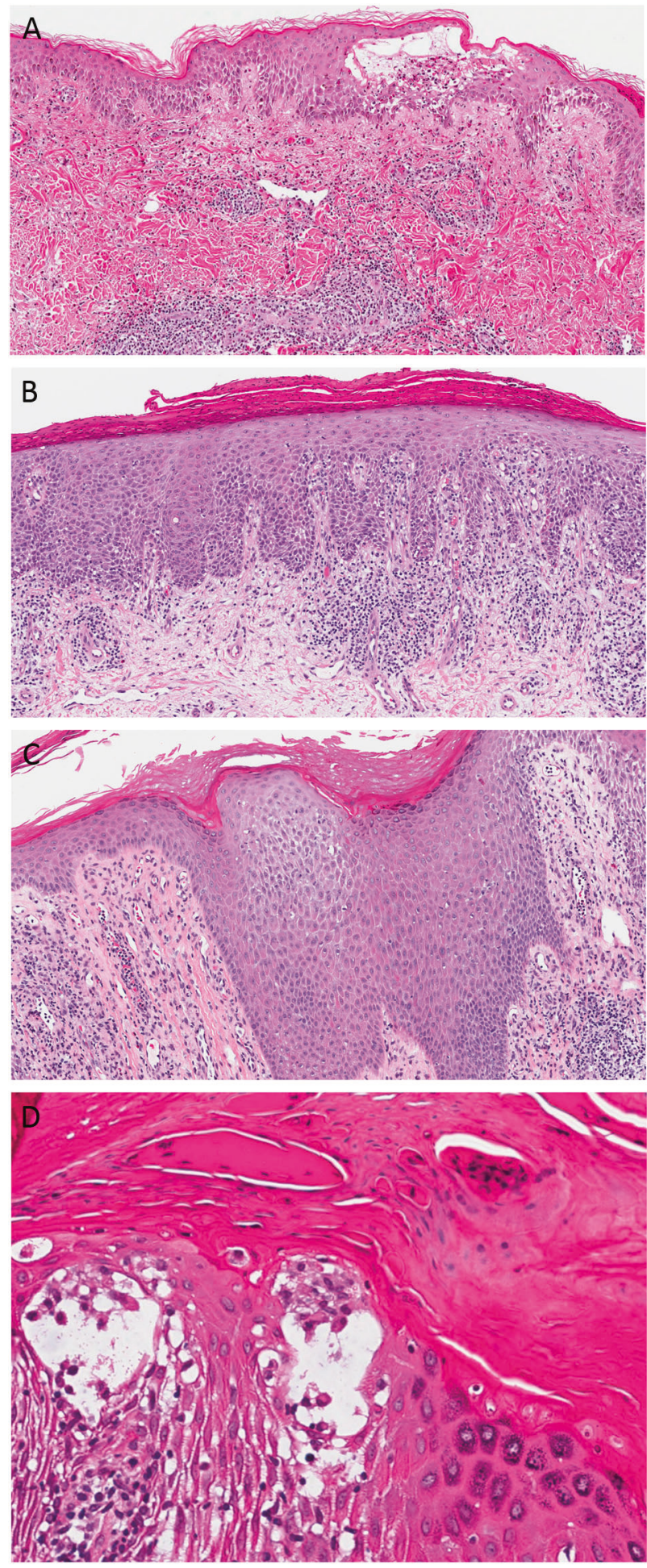

Fig. 1 Spongiotic dermatitis. a There is spongiosis of the epidermis with an intraepidermal spongiotic microvesicle. b In subacute spongiotic dermatitis, there is typically parakeratosis overlying an acanthotic spongiotic epidermis and less dermal edema. $\mathbf{c}$ In chronic spongiotic dermatitis there is often compact hyperkeratosis and a thickened granular layer. d Within the epidermis there are collections of Langerhans cells. When present this is suggestive of allergic contact dermatitis 
presence of collections of Langerhans cells in the epidermis (Fig. 1d) is a clue to the diagnosis, though not entirely specific [8].

The differential diagnosis of the spongiotic dermatitis includes all of the conditions previously mentioned. In fact, it is not possible to reliably distinguish these entities from one another. My typical top line diagnosis is 'Spongiotic dermatitis" with the comment that histologic features could be compatible with an eczematous dermatitis such as contact or atopic dermatitis. If Langerhans cell collections are present in the epidermis, a comment that allergic contact dermatitis should be considered. If superficial dyskeratosis is noted a comment that irritant dermatitis should be considered in the differential. It is also important to consider the possibility of a fungal infection such as candidiasis, especially if neutrophils are present in the stratum corneum. When present, a PAS or GMS stain should be considered to exclude this possibility. The presence of neutrophils in the stratum corneum without serum should prompt consideration of psoriasis. Vulvar psoriasis may have spongiosis and less regular psoriasiform hyperplasia [5, 9]. The presence of eosinophils in the dermal infiltrate argues against psoriasis in most cases [10].

\section{Lichen simplex chronicus}

Lichen simplex chronicus, and the related entity prurigo nodule, is a disease manifestation of persistent scratching. Clinically, it manifests as red to hyperpigmented to white plaques with accentuated skin lines [11, 12]. It is sometimes clinically confused with lichen sclerosus, and that is frequently the submitting diagnosis from the clinician.

Microscopically, lichen simplex chronicus is characterized by compact hyperkeratosis, sometimes with focal parakeratosis, a thickened granular layer and marked acanthosis (Fig. 2a) [13]. In cutaneous lichen simplex chronicus, there is often vertically oriented, thickened collagen bundles in the superficial dermis (Fig. 2b). This finding is often less conspicuous in vulvar biopsies. Classically, there is little inflammation in the underlying dermis. However, it should be pointed out that lichen simplex chronicus may be superimposed on a chronic spongiotic dermatitis, especially in vulvar biopsies [13].

Lichen simplex chronics is a perfect example of an inflammatory dermatosis where it is critical to avoid descriptive diagnosis such as "nonspecific chronic dermatitis". In fact, the findings of lichen simplex chronicus are relatively specific. If the diagnosis of lichen simplex chronicus is rendered, the clinician can more properly treat and counsel the patient in order to break the itch-scratch cycle that perpetuates the disease. A diagnosis of "nonspecific chronic dermatitis" or "nonspecific reactive epidermal change" is not helpful in patient management.
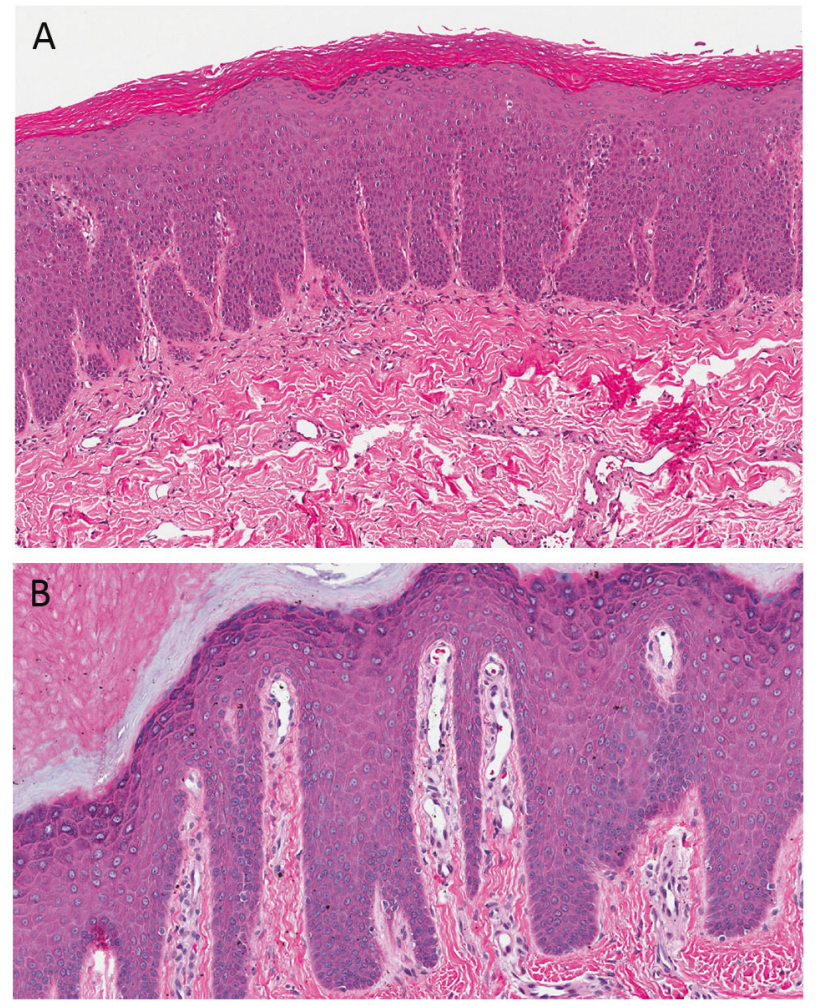

Fig. 2 A Vulvar lichen simplex chronicus demonstrating compact hyperkeratosis overlying an acanthotic epidermis that has a thickened granular layer. Figure 2B. Cutaneous lichen simplex chronicus with vertically oriented thickened collagen bundles in the papillary dermis

\section{Lichen sclerosus}

Classic lichen sclerosus is not a challenging diagnosis. However, in the early inflammatory phase of the disease, it frequently poses a diagnostic challenge. Clinically, early lichen sclerosus does not present as the classic porcelain white atrophic plaques. It may initially present as nonspecific pruritus with burning and an erythematous clinical appearance, mimicking an eczematous process [14].

Microscopically, early lichen sclerosus presents as an interface dermatitis without the classic papillary dermal homogenization. Histologic findings associated with early lichen sclerosus include a lichenoid lymphocytic infiltrate, exocytosis of lymphocytes, dyskeratotic cells at multiple levels of the epidermis, basement membrane thickening, submucosal or superficial dermal fibrosis, perivascular hyalinization, and irregular to psoriasiform epidermal hyperplasia (Fig. 3) [13-17].

The primary histologic differential diagnosis is lichen planus. Both have a lichenoid inflammatory infiltrate, but lichen planus is not associated with basement membrane thickening or epidermal acanthosis. The dyskeratotic cells of lichen planus are concentrated at the dermoepidermal junction and there is limited exocytosis of lymphocytes into 


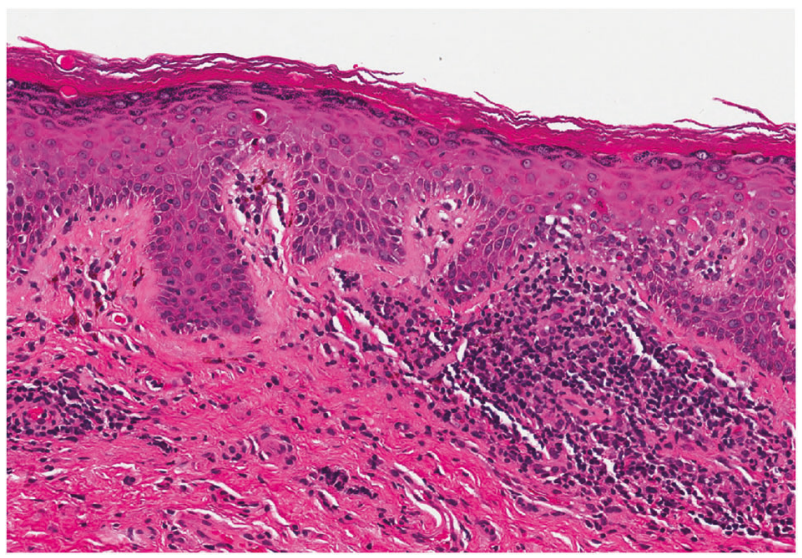

Fig. 3 Early lichen sclerosus. In early lichen sclerosus there is a lichenoid inflammatory infiltrate with fibrosis of the papillary dermis. The epidermis has compact hyperkeratosis, a thickened granular layer, dyskeratosis at multiple levels in the spinous layer, and a thickened basement membrane

the epidermis. In lichen planus the rete pegs have a pointed, sawtooth configuration not seen in lichen sclerosus [15-17]. Mycosis fungoides is another consideration in the differential diagnosis of early lichen sclerosus [18]. Features that can help differentiate early lichen sclerosus focal areas of pronounced sclerosis, restriction of intraepidermal lymphocytes to the lower half of the epidermis and basal vacuolization, features not typically seen in mycosis fungoides. Clonality studies may be helpful, but it should be pointed out that a monoclonal population of $\mathrm{T}$ cells is rarely encountered in early lichen sclerosus [18].

\section{Graft versus host disease}

Biopsies to evaluate for graft versus host disease (GVHD) are relatively frequent specimens in hospitals that have stem cell transplantation programs. It may be seen in between 20 and $80 \%$ of patients with allogeneic stem cell transplantation [19]. Less commonly GVHD is seen in the setting of solid organ transplantation [20]. GVHD was traditionally subdivided into acute and chronic types based on the timing of the disease within the first 100 days after stem cell transplantation [21]. With the changing practices of stem cell transplantation, this old definition is no longer a sufficient. Currently, acute GVHD into classic acute GVHD and persistent, recurrent, or late onset acute GVHD. Acute GVHD is currently defined as having characteristic skin findings, gastrointestinal tract or liver abnormalities, and the absence of features of chronic GVHD irrespective of the timing of the stem cell transplantation. Chronic GVHD is subclassified into classic chronic GVHD based on the presence of distinctive manifestation of chronic GVHD and overlap syndrome in which the patients have features of chronic and acute

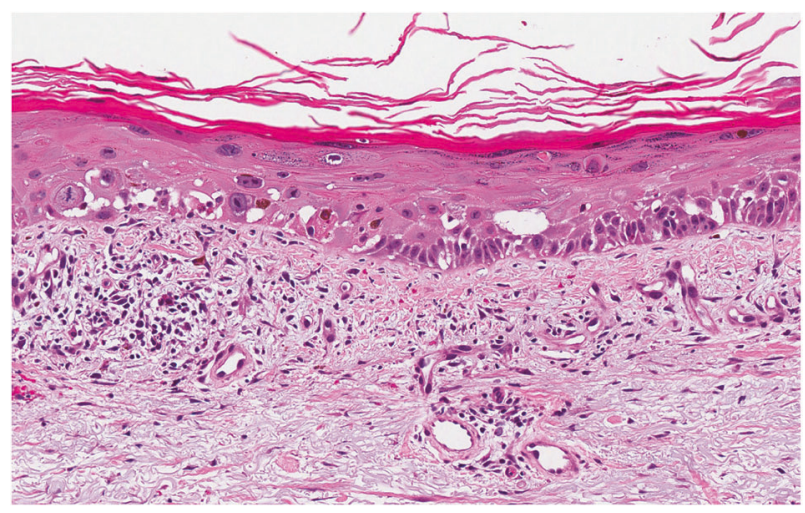

Fig. 4 Acute graft versus host disease with basal vacuolization and lymphocytes tagging dyskeratotic keratinocytes (satellite cell necrosis)

GVHD. The time of onset is no longer a consideration for diagnostic criteria [22, 23].

Typically, acute GVHD has a classic triad of exanthema, diarrhea, and elevated bilirubin levels, though not all patients exhibit the triad [20-24]. Cutaneous manifestations are the most common presenting sign. Patients typically present with a maculopapular, morbilliform eruption that starts on the face, palms, and soles, and subsequently spreads to the trunk and other parts of the body. Involvement of the palms and soles is a clinical finding that helps distinguish acute GVHD from drug eruptions.

Chronic GVHD may be subdivided into nonsclerotic and sclerotic forms [21-24]. The most common nonsclerotic form is lichenoid chronic GVHD (lichen planuslike chronic GVHD). This can clinically overlap with lichen planus, though lichenoid GVHD often involves sites not typically involved by lichen planus, such as the palms, soles, ears, and face. Unlike acute GVHD, lichenoid chronic GVHD also often involves the oral mucosa. The sclerotic forms clinically resemble lichen sclerosus, morphea, or scleroderma.

Microscopically acute GVHD is a vacuolar interface dermatitis characterized by a usually mild superficial perivascular lymphocytic infiltrate with varying amounts of epidermal damage consisting of basal vacuolization and usually some dyskeratotic keratinocytes with satellite cell necrosis (Fig. 4) [22, 25]. Follicles are also commonly affected and may be the initial histologic manifestation [26]. Acute GVHD is graded according to the Lerner system [25]. Briefly, grade I acute GVHD is characterized by basal vacuolization and a mild superficial perivascular infiltrate of lymphocytes. Grade II additionally has dyskeratotic cells. Grade III has cleft formation. In grade IV disease, there is complete loss of the epidermis from the dermis. Grade II acute GVHD is most commonly encountered. The value of grading acute GVHD has been challenged. In a retrospective study of 120 patients, the 
grade of acute GVHD did not correlate with survival, though it was considered important to still establish a diagnosis based on skin biopsy [27].

In lichenoid chronic GVHD, there is compact hyperkeratosis, hypergranulosis, and a variable lichenoid lymphocytic infiltrate with interface change with dyskeratosis (Fig. 5A) [22, 28, 29]. The sclerotic form of acute GVHD shows sclerosis of the dermal collagen with a loss of the normal spaces between reticular dermal collagen bundles and loss of adnexal structures [22, 28, 29]. It should be noted that chronic GVHD is not graded with the Lerner system.

The primary differential diagnosis for acute GVHD is with a drug eruption. In many cases, this distinction may not be possible on histologic findings alone. Eosinophils may be present in the infiltrate of both. If eosinophils are numerous ( $\geq 16 / 10 \mathrm{HPFs}$ ), the diagnosis of a drug eruption should be considered [30]. Less than that and the diagnosis of GVHD cannot be excluded. From a practical standpoint, this patient population has an impaired immune system and my bias is in favor of making the diagnosis of GVHD
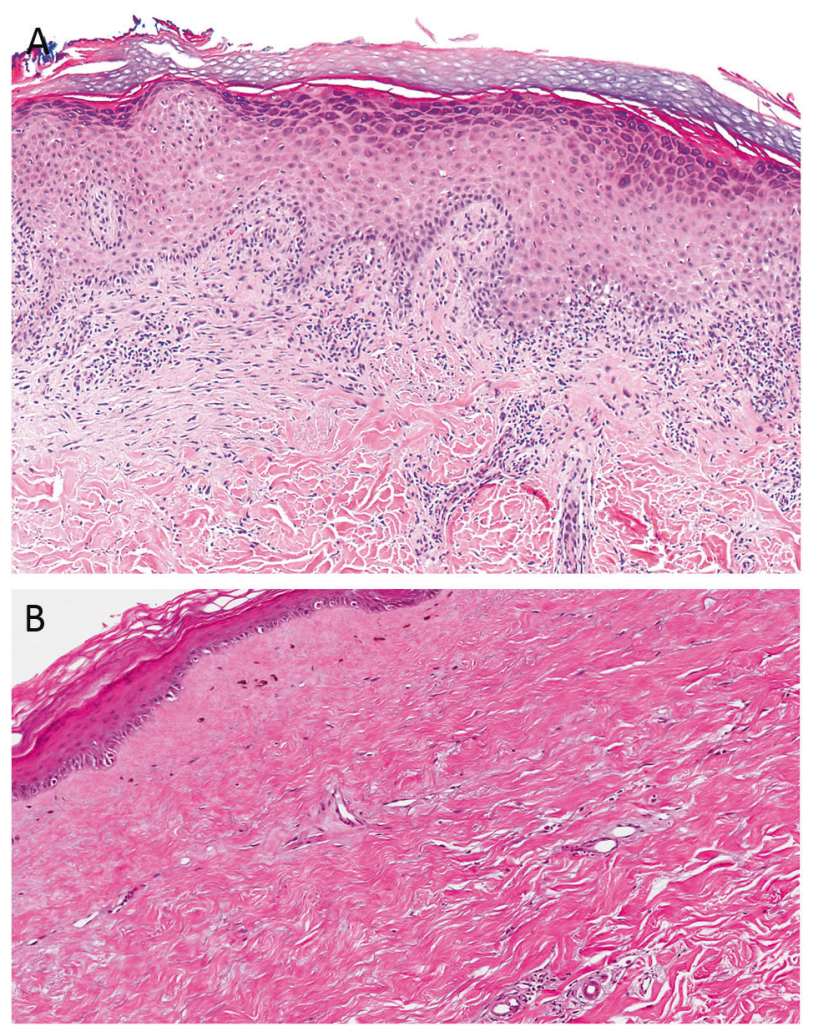

Fig. 5 a Lichenoid chronic graft versus host disease. Note the compact hyperkeratosis and thickened granular layer reminiscent of epidermal changes in lichen planus in association with a lichenoid lymphocytic infiltrate (courtesy of Michael Tetzlaff, MD, PhD, MD Anderson Cancer Center). b Sclerodermoid chronic graft versus host disease is characterized by dermal sclerosis with loss of the normal spaces between collagen bundles of the reticular dermis. Histologically, it resembles morphea and scleroderma unless there is a compelling to the contrary. Acute GVHD also has overlap with erythema multiforme and toxic epidermal necrolysis. The clinical setting should inform the interpretation. Engraftment syndrome histologically resembles acute GVHD, but has a different time course, occurring 10-14 days after stem cell transplantation [31, 32]. It is rare to see acute GVHD prior to 14 days after transplantation. For chronic lichenoid GVHD, the infiltrate is usually less robust than that of cutaneous lichen planus. Chronic lichenoid GVHD is also more likely to have eosinophils and plasma cells. Sclerotic, or sclerodermoid, chronic GVHD histologically resembles morphea and scleroderma (Fig. 5b). The distinction is largely distinguished from its mimics by the clinical setting rather than histology.

\section{Stevens-Johnson syndrome and toxic epidermal necrolysis}

Stevens-Johnson syndrome and toxic epidermal necrolysis are related entities and represent life-threatening drug hypersensitivity reactions [33-38]. They represent one of the few true dermatologic emergencies and are often initially evaluated by frozen section. Therefore the general surgical pathologist needs to be familiar with these entities. They are clinically distinguished by the amount of body surface area involvement [33-38]. For Stevens-Johnson syndrome, $<10 \%$ of the total body surface area is involved, while in toxic epidermal necrolysis $>30 \%$ of the body surface is involved. Patients with $10-30 \%$ of body surface involvement are considered to have Stevens-Johnson syndrome/toxic epidermal necrolysis overlap. Clinically patients often present with prodromal symptoms of fever, sore throat, headaches, muscle ache, nausea and vomiting in varying combinations. The patients then develop a painful rash characterized by irregular, erythematous target lesions that progress to flaccid blisters. Mucous membranes are also involved. Mortality correlates with the amounts of body surface involved and can be as high as $40 \%[38,39]$. In a more recent study, mortality from toxic epidermal necrolysis was $\sim 5 \%$, suggesting that current treatment regimens may be more efficacious and that the risk of mortality may have decreased [40].

Microscopically Steven-Johnson syndrome and toxic epidermal necrolysis are indistinguishable [33, 35]. Early lesions have basal vacuolization with dyskeratotic keratinocytes at multiple levels of the epidermis in association with a sparse to mild perivascular lymphocytic infiltrate with or without a few eosinophils (Fig. 6a). Given that this is an acute onset, the overlying stratum corneum tryptically has a normal basketweave pattern. Over time, the process can progress to confluent epidermal necrosis (Fig. 6B).

The differential diagnosis includes erythema multiforme. Erythema multiforme is histologically indistinguishable 

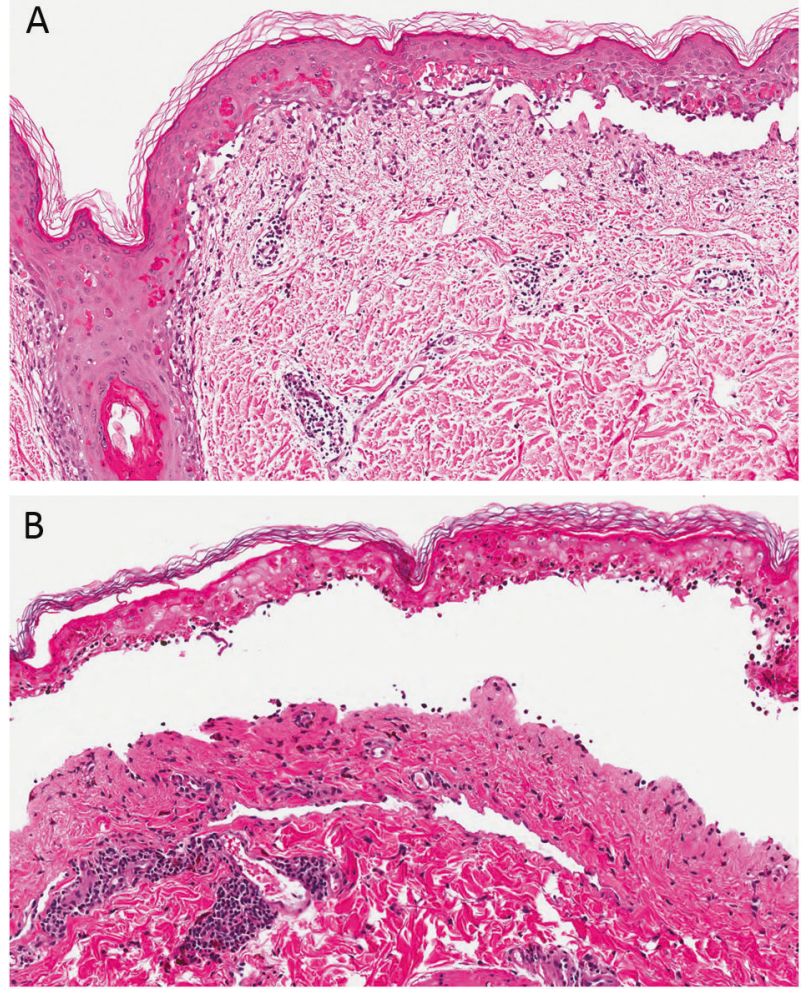

Fig. 6 Toxic epidermal necrolysis. a There is interface change with numerous dyskeratotic keratinocytes and only a mild inflammatory infiltrate. b Later lesions can have full thickness necrosis

from Stevens-Johnson syndrome and toxic epidermal necrolysis. The distinction is based on clinical parameters [33]. Erythema multiforme is a self-limiting and often recurrent eruption. Staphylococcal scalded skin syndrome may clinically mimic toxic epidermal necrolysis and is a frequent clinical diagnostic consideration at the time of frozen section [33]. This disease is mediated by a bacterial toxin that causes a split in the upper epidermis at the level of the granular layer [33, 41, 42]. Histologically, there is acantholysis at the level of the stratum granulosum (Fig. 7). Sometimes there is a subcorneal pustule. Some biopsies may show a complete absence of the stratum corneum. Notably, there is no interface change with keratinocyte necrosis. Therefore, the distinction on frozen section is relatively straightforward. As an aside, for frozen section analysis a punch biopsy cut perpendicular to the axis of the epidermis is preferred for frozen section analysis.

\section{Granuloma annulare}

Granuloma annulare is the prototypical palisading granulomatous dermatitis. Clinically, it usually presents as one or several papules, often in an annular configuration on the distal extremities, especially the hands [43, 44]. Women are more commonly affected than men and it typically

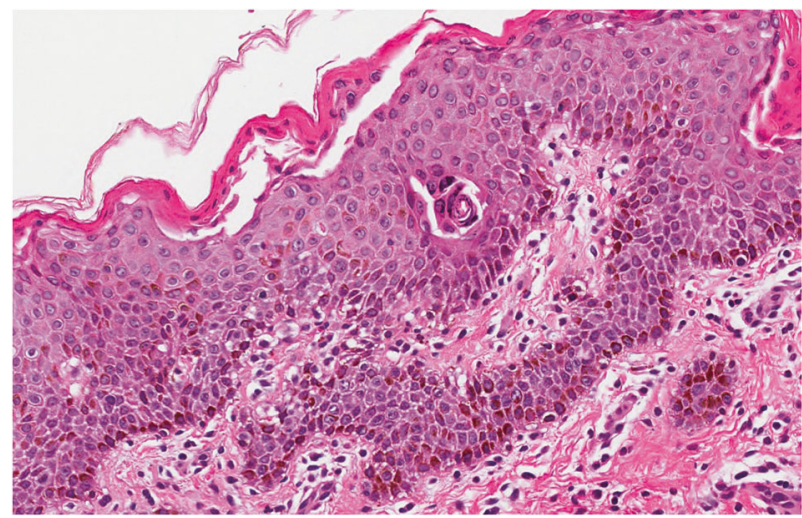

Fig. 7 Staphylococcal scalded skin syndrome. In this disease there is acantholysis at the level of the stratum granulosum. No interface change is present

presents in the first three decades. In about $15 \%$ of patients it may present as a generalized cutaneous eruption. Subcutaneous, or deep, granuloma annulare has a predilection for the lower extremities and is much more common in pediatric patients [43-46].

Microscopically, granuloma annulare is composed of histiocytes, lymphocytes, and some fibroblasts surrounding a zone of altered collagen with increased mucin deposition between the altered collagen bundles (Fig. 8a) [44-48]. The altered collagen at the center of the palisading granuloma often looks more brightly eosinophilic compared with the uninvolved collagen [49]. Eosinophils may also be a part of the infiltrate. In some cases the palisading granuloma is very subtle and the infiltrate surrounds altered collagen bundles in a less defined fashion in what has been termed interstitial granuloma annulare (Fig. 8b) [44, 47]. In subcutaneous granuloma annulare, the finding are centered in the deep dermis and subcutis (Fig. 8c), though areas of conventional granuloma anulare may be present in about $25 \%$ of cases [45, 46]. Rare cases may exhibit sarcoid-like granulomas [50]. Perforating granuloma annulare in which the palisading granuloma is associated with transepidermal elimination of necrobiotic collagen is another rare variant and has been associated with tattoos [51-54].

One of the classic differential diagnoses for granuloma annulare is necrobiosis lipoidica. Necrobiosis lipoidica typically presents as red-brown to yellowish plaques on the lower legs [55, 56]. Microscopically, it affects the entire dermis unlike the more regional pattern of granuloma annulare. It also has a tiered arrangement of inflammatory cells composed of histiocytes, lymphocytes, and plasma cells alternating with horizontal zones of necrobiotic collagen in an appearance that has been likened to that of a layer cake or piece of bacon (Fig. 9) [55, 56]. Therefore the low power architecture usually allows distinction from granuloma annulare. Plasma cells, typically present in necrobiosis lipoidica, are not a feature of granuloma annulare. 

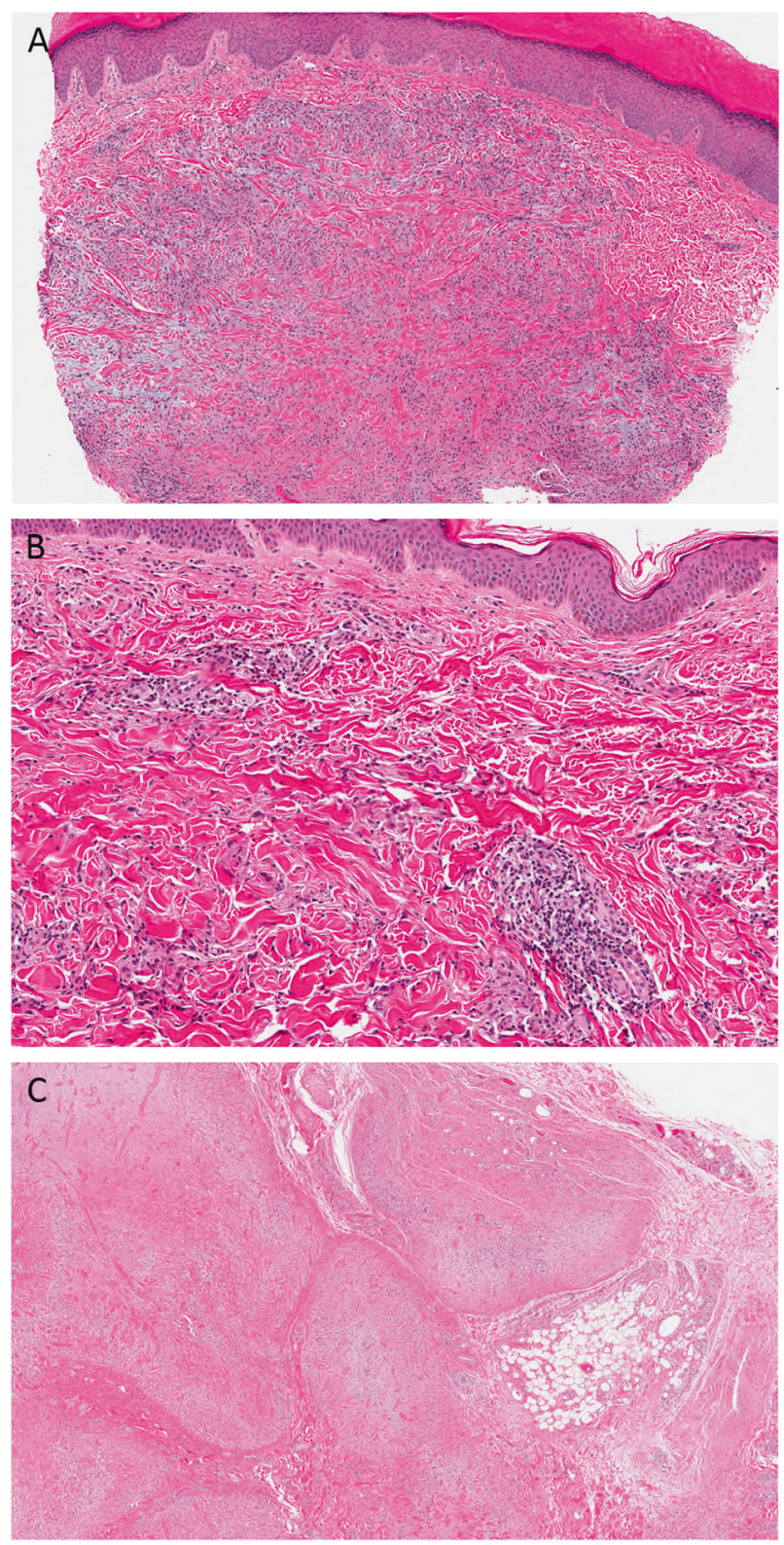

Fig. 8 Granuloma annulare. a Typical granuloma annulare with a palisading granuloma characterized by histiocytes surrounding altered collagen fibers associated with increased dermal mucin. b In interstitial granuloma annulare, the palisading granuloma is not well developed and the histiocytes intercalate between altered collagen bundles. c In deep granuloma annulare, the palisading granulomas are in the subcutis or deep dermis

Rheumatoid nodule is another entity in the differential diagnosis that occurs deeper in the dermis or subcutis that classic granuloma annulare and the palisading granulomas have a sharper border (Fig. 10) [57, 58]. Centrally, within the granuloma of rheumatoid nodule, there is acellular brightly eosinophilic fibrin rather than altered collagen bundles.

Actinic granuloma presents in sun-damaged skin of the upper body of middle-aged and older patients [59, 60].

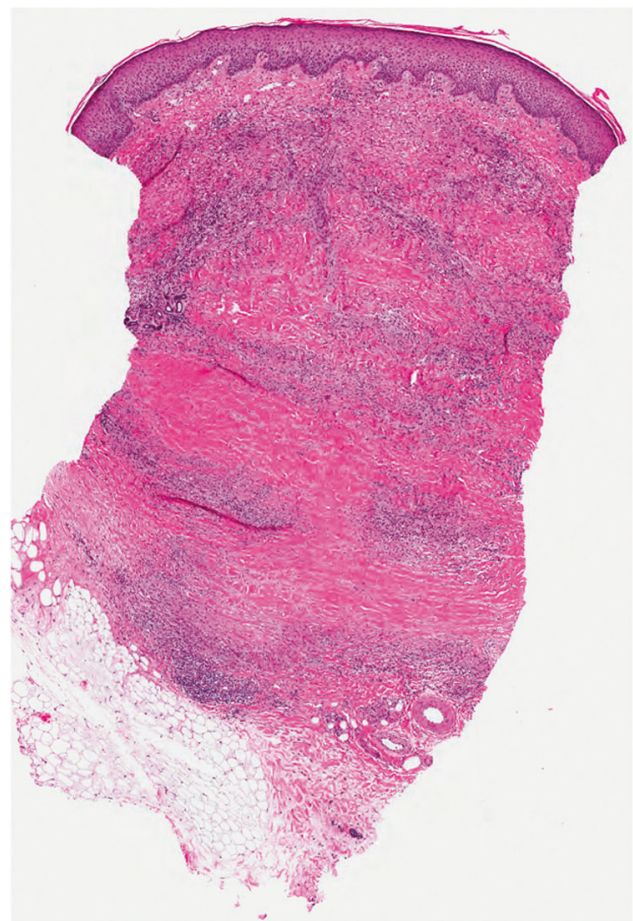

Fig. 9 Necrobiosis lipoidica. There is tiered arrangement of inflammatory cells separated by zones of necrobiotic collagen

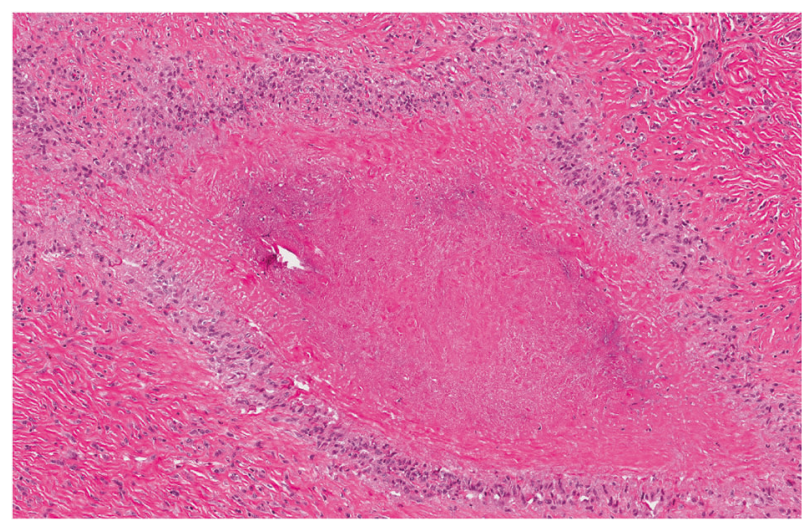

Fig. 10 Rheumatoid nodule with well demarcated palisading granuloma

Microscopically, it is similar to granuloma annulare in that it is composed of palisading granulomas, but the granulomas are centered on elastotic collagen fibers without true necrobiosis (Fig. 11).

An important neoplasm in the differential diagnosis is epithelioid sarcoma, which can sometimes have the appearance of palisading granuloma on low magnification [61-63] (Fig. 12). The tumor cells of epithelioid sarcoma have more cytologic atypia than the histiocytes of granuloma annulare and are immunoreactive for cytokeratin. In most cases this is not a difficult distinction, but if there is ever any doubt, a simple immunohistochemical stain for cytokeratin can resolve this differential. 


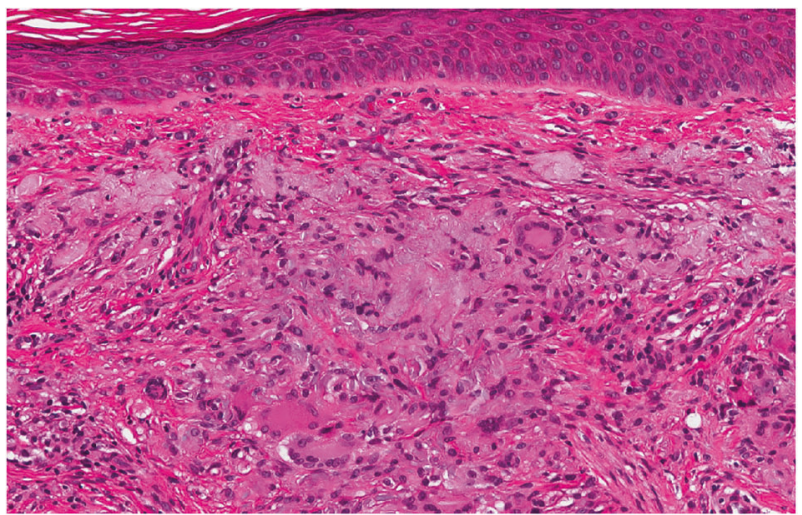

Fig. 11 Actinic granuloma. Granulomatous inflammation in the dermis surrounding elastotic collagen bundles
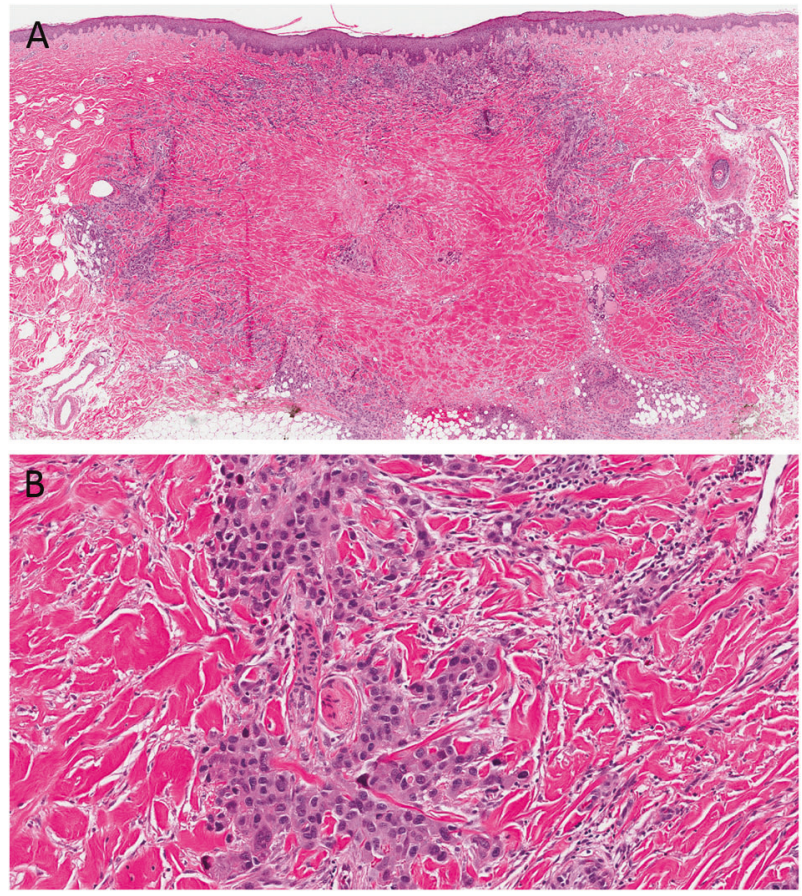

Fig. 12 Epithelioid sarcoma. a Some cases of epithelioid sarcoma mimic granuloma annulare at low magnification. b At high power the lesional cells usually demonstrate increased atypia compared to granuloma annulare

\section{Pyoderma gangrenosum}

Pyoderma gangrenosum is a poorly understood condition characterized by large, painful ulcers that usually presents in middle-aged patients, women somewhat more commonly than men $[64,65]$. The lesions have red-purple edges and undermined borders. The ulcers often persist for many months to years. While the etiology of pyoderma gangrenosum is uncertain, it has been linked to other diseases, especially inflammatory bowel disease, where it has been reported in up to $2 \%$ of patients with this condition $[66,67]$. It has also been associated with connective tissue diseases, joint disease,

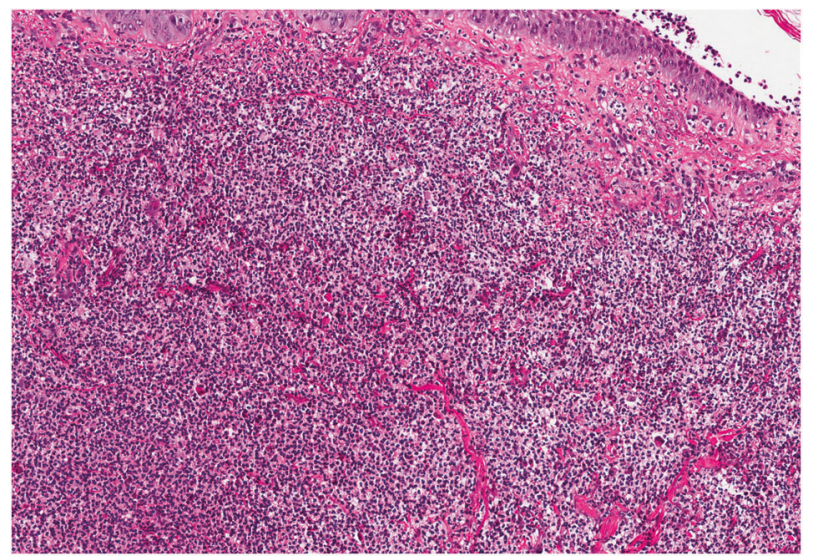

Fig. 13 Pyoderma gangrenosum. a Biopsy from the edge of the ulcer demonstrating the dense neutrophilic infiltrate in the dermis

hematologic disorders, infections, neoplasms, and medications.[64-69]. Although most present as ulcers, bullous, pustular, and vegetative forms have been described. A characteristic feature of pyoderma gangrenosum is pathergy, where lesions develop in the sites of trauma, including surgical sites [70]. This is seen in up to $50 \%$ of patients.

According to a recently published consensus statement, a biopsy of the wound edge demonstrating a neutrophilic infiltrate is the single major criterion to help establish the diagnosis [71]. Eight minor criteria include (1) Exclusion of infection; (2) Pathergy; (3) History of inflammatory bowel diseases or inflammatory arthritis; (4) History of papule, pustule, or vesicle ulcerating within 4 days of appearing; (5) Peripheral erythema, undermining border, and tenderness at ulceration site; (6) Multiple ulcerations, at least one on an anterior lower leg; (7) Cribriform or "wrinkled paper" scar (s) at healed ulcer sites; and (8) Decreased ulcer size within one month of initiating immunosuppressive medication(s) [69]. Establishing the diagnosis requires the major criterion and at least four minor criteria.

Microscopically, lesions of pyoderma gangrenosum demonstrate a dense neutrophilic infiltrate (Fig. 13). At the edge of the ulcer the epidermis may have a rolled border. While these histologic features are characteristic, they are nonspecific.

The differential diagnosis is primarily that of an infectious process, which is ideally evaluated by tissue cultures. Special stains to detect fungal or bacterial organisms can be performed on biopsies but are less sensitive. Sweet syndrome typically lacks ulceration and has more karyorrhexis. It cannot be emphasized enough that the diagnosis of pyoderma gangrenosum, as discussed above, also requires detailed knowledge of clinical parameters that may not be available to the pathologist. In fact, I typically state that establishing the diagnosis of pyoderma gangrenosum is largely based on clinicopathologic correlation. 


\section{Calciphylaxis}

Calciphylaxis is the result of abnormal calcium/phosphate metabolism that typically present as bilateral, painful, gangrenous lesions in fat rich areas, especially the thighs [72-75]. It may also involve, the buttocks, breasts, hands, penis, and exceptionally, the heart [72-82]. Patients have well-delineated, livedoid, violaceous plaques with ulceration. Calciphylaxis is most commonly seen in the setting of chronic renal failure and may affect $1-4 \%$ of patients on dialysis [72-75]. Less commonly, it is seen in nonuremic patients with primary hyperparathyroidism, underlying malignancies, alcoholic liver disease, connective tissue disease, obesity, diabetes mellitus, protein $\mathrm{C}$ and $\mathrm{S}$ deficiency, warfarin treatment, and prior corticosteroid use [83-86]. Calciphylaxis is associated with mortality in up to $60 \%$ of patients, so accurate diagnosis is paramount [72].

Histologically, calciphylaxis is characterized by calcification of small to medium sized vessels and capillaries in between adipocytes in the subcutis (Fig. 14a) [87-89]. Vascular thrombosis is also commonly present (Fig. 14b). There is associated noninflammatory fat necrosis of the subcutis. In a large series by Hoang and colleagues, the most sensitive and specific histologic features for establishing the diagnosis of calciphylaxis are stippled calcification of the subcutis, chunky calcification, and calcification of any size vessel, with stippled calcification having a specificity approaching $100 \%$ (Fig. 14c) [87]. In practice, the calcification is usually evident on routine histologic sections, but a von Kossa stain can be used to highlight calcium deposition in difficult cases [87-89]. It should be emphasized that the diagnosis of calciphylaxis requires examination of a generous sample of subcutaneous fat. Biopsies without such sampling are inadequate to exclude calciphylaxis, and pathologists should not hesitate to recommend additional sampling if calciphylaxis is suspected clinically in the setting of a superficial biopsy.

The differential diagnosis can include thrombotic vasculopathy, chronic stasis dermatitis, and peripheral artery disease. Calcification of small vessels is not typically seen in those entities [89]. Theoretically erythema nodosum or erythema induratum/nodular vasculitis could be considered. Both of these conditions demonstrate significant inflammation rather than the relatively noninflammatory fat necrosis of calciphylaxis [90]. Lipodermatosclerosis is similarly noninflammatory, but has cystic change in the fat rather than diffuse fat necrosis [90]. None of these conditions has calcification of vessels.

\section{Compliance with ethical standards}

Conflict of interest The author declares that he has no conflict of interest.

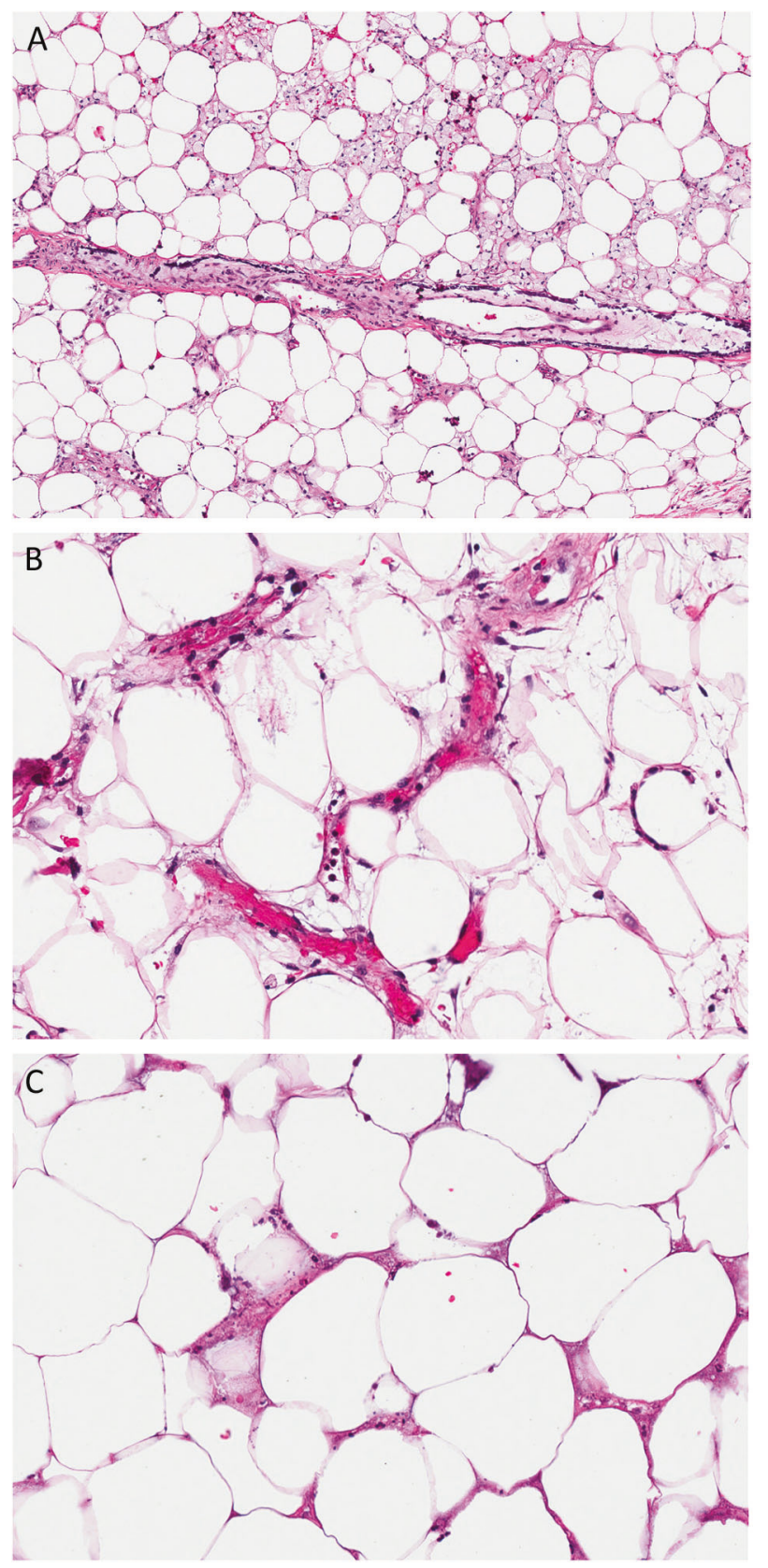

Fig. 14 Calciphylaxis. a Calcium deposition in medium sized vessel with associated fat necrosis. b Vascular thrombosis is commonly present. c Stippled calcification of calciphylaxis

Publisher's note Springer Nature remains neutral with regard to jurisdictional claims in published maps and institutional affiliations.

\section{References}

1. Singh S, Grummer SE, Hancox JG, Sangueza OP, Feldman SR. The extent of dermatopathology education: a comparison of pathology and dermatology. J Am Acad Dermatol. 2005;53:694-7.

2. Ackerman AB. Histologic diagnosis of inflammatory skin diseases: a method by pattern analysis. Philadelphia: Lea \& Febinger; 1978. 
3. Ackerman AB. Histologic diagnosis of inflammatory skin diseases: an algorithmic method based on pattern analysis. Baltimore: Williams \& Wilkins; 1997.

4. Pichardo-Geisinger R. Atopic and Contact Dermatitis of the Vulva. Obstet Gynecol Clin North Am. 2017;44:371-8.

5. Hoang MP, Reutter J, Papalas JA, Edwards L, Selim MA. Vulvar inflammatory dermatoses: an update and review. Am J Dermatopathol. 2014;36:689-704.

6. Schlosser BJ. Contact dermatitis of the vulva. Dermatol Clin. 2010;28:697-706.

7. Woodruff CM, Trivedi MK, Botto N, Kornik R. Allergic contact dermatitis of the vulva. Dermatitis. 2018;29:233-43.

8. Rosa G, Fernandez AP, Vij A, et al. Langerhans cell collections, but not eosinophils, are clues to a diagnosis of allergic contact dermatitis in appropriate skin biopsies. J Cutan Pathol. 2016;43: 498-504.

9. Kapila S, Bradford J, Fischer G. Vulvar psoriasis in adults and children: a clinical audit of 194 cases and review of the literature. J Low Genit Trac Dis. 2012;16:364-71.

10. Rosa G, Fernandez AP, Schneider S, Billings SD. Eosinophils are rare in biopsy specimens of psoriasis vulgaris. J Cutan Pathol. 2017;44:1027-32.

11. Chibnall R. Vulvar pruritus and lichen simplex chronicus. Obstet Gynecol Clin North Am. 2017;44:379-88.

12. Guerrero A, Venkatesan A. Inflammatory vulvar dermatoses. Clin Obstet Gynecol. 2015;58:464-75.

13. Chan MP, Zimarowski MJ. Vulvar dermatoses: a histopathologic review and classification of 183 cases. J Cutan Pathol. 2015;42:510-8

14. Regauer S, Liegl B, Reich O. Early vulvar lichen sclerosus: a histopathological challenge. Histopathology. 2005;47:340-7.

15. Fung MA, LeBoit PE. Light microscopic criteria for the diagnosis of early vulvar lichen sclerosus: a comparison with lichen planus. Am J Surg Pathol. 1998;22:473-8.

16. LeBoit PE. A thickened basement membrane is a clue to... lichen sclerosus! Am J Dermatopathol. 2000;22:457-8.

17. Lewin MR, Hick RW, Selim MA. Lichenoid dermatitis of the vulva: diagnosis and differential diagnosis for the gynecologic pathologist. Adv Anat Pathol. 2017;24:278-93.

18. Citarella L, Massone C, Kerl H, Cerroni L. Lichen sclerosus with histopathologic features simulating early mycosis fungoides. Am J Dermatopathol. 2003;25:463-5.

19. Martin PJ, Rizzo JD, Wingard JR, et al. First- and secondline systemic treatment of acute graft-versus-host disease: recommendations of the American Society of Blood and Marrow Transplantation. Biol Blood Marrow Transplant. 2012;18: 1150-63.

20. Kim GY, Schmelkin LA, Davis MDP, et al. Dermatologic manifestations of solid organ transplantation-associated graftversus-host disease: a systematic review. J Am Acad Dermatol. 2018;78:1097-.e1.

21. Strong Rodrigues K, Oliveira-Ribeiro C, de Abreu Fiuza Gomes S, Knobler R. Cutaneous graft-versus-host disease: diagnosis and treatment. Am J Clin Dermatol. 2018;19:33-50.

22. Kavand S, Lehman JS, Hashmi S, Gibson LE, El-Azhary RA. Cutaneous manifestations of graft-versus-host disease: role of the dermatologist. Int J Dermatol. 2017;56:131-40.

23. Filipovich $A H$, Weisdorf $D$, Pavletic $S$, et al. National Institutes of Health consensus development project on criteria for clinical trials in chronic graft-versus host disease: I. Diagnosis and staging working group report. Biol Blood Marrow Transplant. 2005;11:945-56.

24. Jagasia MH, Greinix HT, Arora M, et al. National Institutes of Health Consensus Development Project on criteria for clinical trials in chronic graft-versus-host disease: I. The 2014 Diagnosis and Staging Working Group report. Biol Blood Marrow Transplant. 2015;21:389-401.e1.
25. Lerner KG, Kao GF, Storb R, Buckner CD, Clift RA, Thomas ED. Histopathology of graft-vs-host reaction (GvHR) in human recipients of marrow from HLA-matched sibling donors. Transpl Proc. 1974;6:367-71.

26. Friedman KJ, LeBoit PE, Farmer ER. Acute follicular graft-vshost reaction. A distinct clinicopathologic presentation. Arch Dermatol. 1988;124:688-91.

27. Hogenes $\mathrm{MCH}$, Te Boome LCJ, van der Valk DC, et al. Clinical versus histological grading in the assessment of cutaneous graft versus host disease. Eur J Med Res 2019;24:19.

28. Ballester-Sánchez R, Navarro-Mira M, Sanz-Caballer J, BotellaEstrada R. Review of cutaneous graft-vs-host Disease. Actas Dermosifiliogr. 2016;107:183-93.

29. Hillen U, Häusermann P, Massi D, et al. Consensus on performing skin biopsies, laboratory workup, evaluation of tissue samples and reporting of the results in patients with suspected cutaneous graftversus-host disease. J Eur Acad Dermatol Venereol. 2015;29:948-54.

30. Weaver J, Bergfeld WF. Quantitative analysis of eosinophils in acute graft-versus-host disease compared with drug hypersensitivity reactions. Am J Dermatopathol. 2010;32:31-4.

31. Spitzer TR. Engraftment syndrome: double-edged sword of hematopoietic cell transplants. Bone Marrow Transplant. 2015;50: 469-75.

32. Cornell RF, Hari P, Drobyski WR. Engraftment syndrome after autologous stem cell transplantation: an update unifying the definition and management approach. Biol Blood Marrow Transplant. 2015;21:2061-8.

33. Lerch M, Mainetti C, Terziroli Beretta-Piccoli B, Harr T. Current perspectives on stevens-johnson syndrome and toxic epidermal necrolysis. Clin Rev Allergy Immunol. 2018;54:147-76.

34. Schneider JA, Cohen PR. Stevens-Johnson syndrome and toxic epidermal necrolysis: a concise review with a comprehensive summary of therapeutic interventions emphasizing supportive measures. Adv Ther. 2017;34:1235-44.

35. Wong A, Malvestiti AA, Hafner Mde F. Stevens-Johnson syndrome and toxic epidermal necrolysis: a review. Rev Assoc Med Bras (1992). 2016;62:468-73.

36. Dodiuk-Gad RP, Chung WH, Valeyrie-Allanore L, Shear NH. Stevens-Johnson syndrome and toxic epidermal necrolysis: an update. Am J Clin Dermatol. 2015;16:475-93.

37. Mockenhaupt M. Stevens-Johnson syndrome and toxic epidermal necrolysis: clinical patterns, diagnostic considerations, etiology, and therapeutic management. Semin Cutan Med Surg. 2014;33:10-6.

38. Revuz J, Penso D, Roujeau JC, Guillaume JC, Payne CR, Wechsler $\mathrm{J}$, et al. Toxic epidermal necrolysis. Clinical findings and prognosis factors in 87 patients. Arch Dermatol. 1987;123:1160-5.

39. Roujeau JC. Severe drug-induced blistering disorders. Rev Rhum Engl Ed 1997;64:5-9.

40. Yamane Y, Matsukura S, Watanabe Y, et al. Retrospective analysis of Stevens-Johnson syndrome and toxic epidermal necrolysis in 87 Japanese patients-Treatment and outcome. Allergol Int. 2016;65:74-81.

41. Handler MZ, Schwartz RA. Staphylococcal scalded skin syndrome: diagnosis and management in children and adults. J Eur Acad Dermatol Venereol. 2014;28:1418-23.

42. Patel GK, Finlay AY. Staphylococcal scalded skin syndrome: diagnosis and management. Am J Clin Dermatol. 2003;4:165-75.

43. Keimig EL. Granuloma Annulare. Dermatol Clin. 2015;33:315-29.

44. Piette EW, Rosenbach M. Granuloma annulare: clinical and histologic variants, epidemiology, and genetics. J Am Acad Dermatol. 2016;75:457-65.

45. Requena L, Fernández-Figueras MT. Subcutaneous granuloma annulare. Semin Cutan Med Surg. 2007;26:96-9.

46. McDermott MB, Lind AC, Marley EF, Dehner LP. Deep granuloma annulare (pseudorheumatoid nodule) in children: clinicopathologic study of 35 cases. Pediatr Dev Pathol. 1998;1:300-8. 
47. Ronen S, Rothschild M, Suster S. The interstitial variant of granuloma annulare: clinicopathologic study of 69 cases with a comparison with conventional granuloma annulare. J Cutan Pathol. 2019; https://doi.org/10.1111/cup.13455.

48. Stefanaki K, Tsivitanidou-Kakourou T, Stefanaki C, et al. Histological and immunohistochemical study of granuloma annulare and subcutaneous granuloma annulare in children. J Cutan Pathol. 2007;34:392-6.

49. Billings SD, Cotton J. Inflammatory dermatopathoogy: a pathologist's survival guide. 2nd ed. New York: Springer; 2016.

50. Cohen PR, Carlos CA. Granuloma Annulare Mimicking Sarcoidosis: Report of Patient With Localized Granuloma Annulare Whose Skin Lesions Show 3 Clinical Morphologies and 2 Histology Patterns. Am J Dermatopathol. 2015;37:547-50.

51. Alves J, Barreiros H, Bártolo E. Perforating granuloma annulare an unusual subtype of a common disease. Healthc (Basel). 2014; 2:338-45.

52. Penas PF, Jones-Caballero M, Fraga J, Sánchez-Pérez J, GarcíaDíez A. Perforating granuloma annulare. Int J Dermatol. 1997; 36:340-8.

53. Madan NK, Vallonthaiel AG, Arava S, Ali MF, Goyal M, Singh MK. Perforating granuloma annulare in a young male following application of the tattoo. Indian Dermatol Online J. 2015;6:296-8.

54. Bianco P, Mugheddu C, Faa G, Pilloni L, Rongioletti F. Perforating granuloma annulare within the red dye of a tattoo. G Ital Dermatol Venereol. 2017;152:684-6.

55. Lowitt MH, Dover JS. Necrobiosis lipoidica. J Am Acad Dermatol. 1991;25:735-48.

56. Sibbald C, Reid S, Alavi A. Necrobiosis Lipoidica. Dermatol Clin. 2015;33:343-60.

57. García-Patos V. Rheumatoid nodule. Semin Cutan Med Surg. 2007;26:100-7.

58. Lynch JM, Barrett TL. Collagenolytic (necrobiotic) granulomas: part II-the 'red' granulomas. J Cutan Pathol. 2004;31:409-18.

59. Steffen C. Actinic granuloma (O'Brien). J Cutan Pathol. 1988;15: 66-74.

60. Gutiérrez-González E, Pereiro M Jr, Toribio J. Elastolytic actinic giant cell granuloma. Dermatol Clin. 2015;33:331-41.

61. Wick MR, Manivel JC. Epithelioid sarcoma and isolated necrobiotic granuloma: a comparative immunocytochemical study. J Cutan Pathol. 1986;13:253-60.

62. Cançado CG, Vale FR, Bacchi CE. Subcutaneous (deep) granuloma annulare in children: a possible mimicker of epithelioid sarcoma. Fetal Pediatr Pathol. 2007;26:33-9.

63. Lopez-Rios F, Rodriguez-Peralto JL, Castano E, Gil R. Epithelioid sarcoma masquerading as perforating granuloma annulare. Histopathology. 1997;31:102-3.

64. Alavi A, French LE, Davis MD, Brassard A, Kirsner RS. Pyoderma Gangrenosum: an update on pathophysiology, diagnosis and treatment. Am J Clin Dermatol. 2017;18:355-72.

65. Cozzani E, Gasparini G, Parodi A. Pyoderma gangrenosum: a systematic review. G Ital Dermatol Venereol. 2014;149:587-600.

66. Feliciani C, De Simone C, Amerio P. Dermatological signs during inflammatory bowel diseases. Eur Rev Med Pharm Sci. 2009;13 (Mar):15-21.

67. Weizman AV, Huang B, Targan S, et al. Pyoderma gangrenosum among patients with inflammatory bowel disease: a descriptive cohort study. J Cutan Med Surg. 2015;19:125-31.

68. Ruocco E, Sangiuliano S, Gravina AG, Miranda A, Nicoletti G. Pyoderma gangrenosum: an updated review. J Eur Acad Dermatol Venereol. 2009;23:1008-17.
69. Wang JY, French LE, Shear NH, Amiri A, Alavi A. Drug-induced pyoderma gangrenosum: a review. Am J Clin Dermatol. 2018; 19:67-77.

70. Zuo KJ, Fung E, Tredget EE, Lin AN. A systematic review of post-surgical pyoderma gangrenosum: identification of risk factors and proposed management strategy. J Plast Reconstr Aesthet Surg. 2015;68:295-303.

71. Maverakis E, Ma C, Shinkai K, et al. Diagnostic criteria of ulcerative pyoderma gangrenosum: a delphi consensus of international experts. JAMA Dermatol. 2018;154:461-6.

72. Jeong HS, Dominguez AR. Calciphylaxis: controversies in pathogenesis, diagnosis and treatment. Am J Med Sci. 2016;351: 217-27.

73. Nigwekar SU, Thadhani R, Brandenburg VM. Calciphylaxis. N Engl J Med. 2018;378:1704-14.

74. Nigwekar SU. Calciphylaxis. Curr Opin Nephrol Hypertens. 2017;26:276-81.

75. Ahmed MM, Zakir A, Ahsraf MF, et al. Chronic kidney disease and calciphylaxis: a literature review. Cureus. 2018;10:e3334.

76. Koratala A, Ejaz AA, Mohandas R. Calciphylaxis of the breast: a rare metabolic complication of kidney disease. BMJ Case Rep. 2016;9(Aug):2016.

77. Cathenis K, Goossens D, Vertriest R, Coppens M, Hamerlijnck R. Breast infarction due to calciphylaxis after coronary artery bypass grafting. Ann Thorac Surg. 2011;91:1603-6.

78. Kazanji N, Falatko J, Neupane S, Reddy G. Calciphylaxis presenting as digital ischemia. Intern Emerg Med. 2015;10:529-30.

79. Dear J, Brookes J, Mansell M, Laing C. Calciphylaxis. Lancet. 2003;362:1707.

80. Karpman E, Das S, Kurzrock EA. Penile calciphylaxis: analysis of risk factors and mortality. J Urol. 2003;169:2206-9.

81. Gallimore GG, Curtis B, Smith A, Benca M. Curious case of calciphylaxis leading to acute mitral regurgitation. BMJ Case Rep. 2014;2014: pii: bcr2013201803. https://doi.org/10.1136/bcr-2013201803.

82. Tom CW, Talreja DR. Heart of stone. Mayo Clin Proc. 2006; $81: 335$.

83. Nigwekar SU, Wolf M, Sterns RH, Hix JK. Calciphylaxis from nonuremic causes: a systematic review. Clin J Am Soc Nephrol. 2008;3:1139-43.

84. Bajaj R, Courbebaisse M, Kroshinsky D, Thadhani RI, Nigwekar SU. Calciphylaxis in Patients With Normal Renal Function: a case series and systematic review. Mayo Clin Proc. 2018;93(Sep):1202-12.

85. El-Azhary RA, Patzelt MT, McBane RD, et al. Calciphylaxis: a disease of pannicular thrombosis. Mayo Clin Proc. 2016;91 (Oct):1395-402.

86. Yu WY, Bhutani T, Kornik R, et al. Warfarin-associated nonuremic calciphylaxis. JAMA Dermatol. 2017;153(Mar):309-14.

87. Mochel MC, Arakaki RY, Wang G, Kroshinsky D, Hoang MP. Cutaneous calciphylaxis: a retrospective histopathologic evaluation. Am J Dermatopathol. 2013;35:582-6.

88. Chen TY, Lehman JS, Gibson LE, Lohse CM, El-Azhary RA. Histopathology of calciphylaxis: cohort study with clinical correlations. Am J Dermatopathol. 2017;39:795-802.

89. McMullen ER, Harms PW, Lowe L, Fullen DR, Chan MP. Clinicopathologic features and calcium deposition patterns in calciphylaxis: comparison with gangrene, peripheral artery disease, chronic stasis, and thrombotic vasculopathy. Am J Surg Pathol. 2019;43:1273-81.

90. Wick MR. Panniculitis: a summary. Semin Diagn Pathol. 2017; 34:261-72. 